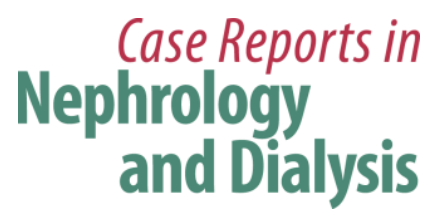

\title{
Effective Management of Peritoneal Dialysis-Associated Hydrothorax in a Child: A Case Report
}

\author{
${\text { Cahyani Gita Ambarsari }{ }^{a} \quad \text { Evita Karianni Bermanshah }}^{a}$ \\ Muhammad Arza Putra ${ }^{b}$ Farhan Haidar Fazlur Rahman ${ }^{a}$ \\ Sudung Oloan Pardede ${ }^{a}$ \\ aDepartment of Child Health, Faculty of Medicine, Universitas Indonesia, Cipto \\ Mangunkusumo Hospital, Jakarta Pusat, Indonesia; 'bepartment of Surgery, Faculty of \\ Medicine, Universitas Indonesia, Cipto Mangunkusumo Hospital, Jakarta Pusat, Indonesia
}

\section{Keywords}

End-stage renal disease · Peritoneal dialysis · Pleural effusion · Pleurodesis

\begin{abstract}
Peritoneal dialysis (PD) confers many advantages, including a better quality of life for children with end-stage renal disease; however, the procedure is associated with several complications, including pleuroperitoneal leaks. Here, we report an unusual case of hydrothorax caused by long-term PD in a child, which was further complicated by pneumonia. A 9-year-old boy who had received CAPD for 22 months presented with dyspnea, swelling, and increased body weight. Chest tube drainage yielded $500 \mathrm{~mL}$ of transudative fluid. Computed tomography peritoneography revealed increased outflow from the peritoneum to the pleural cavity. PD was suspended, and hemodialysis (HD) was initiated. Video-assisted thoracoscopic surgery was performed; however, because the patient had pneumonia during hospitalization, pleural adhesions with a septated appearance occurred. This resulted in difficulties identifying pleuroperitoneal fistula (PPF). Right pleural effusion resolved following pleurodesis using bleomycin.
\end{abstract}



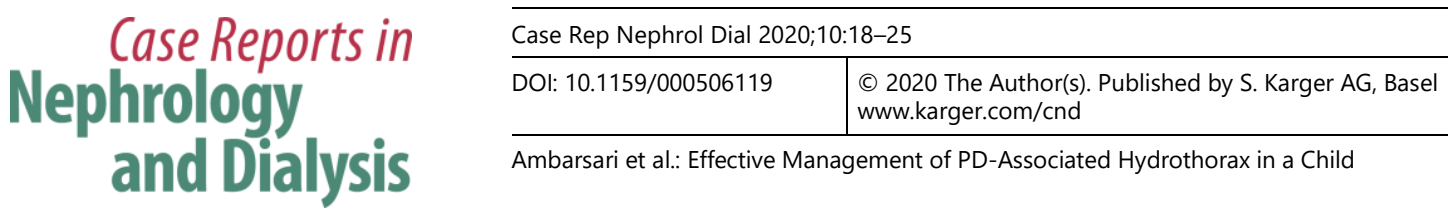

Regular HD was performed for 10 weeks, and PD was subsequently reinitiated. There was no recurrence of hydrothorax during long-term follow-up. We suspect that the underlying mechanism of hydrothorax in our patient was associated with a PPF that formed either due to a congenital diaphragmatic defect or an acquired defect, resulting in dialysate leakage. Our case demonstrates that a temporary switch from PD to HD, accompanied by pleurodesis, may help resolve hydrothorax that occurs as a complication of long-term PD.

(C) 2020 The Author(s)

Published by S. Karger AG, Basel

\section{Introduction}

Hydrothorax secondary to a pleuroperitoneal fistula (PPF) is a rare complication of longterm peritoneal dialysis (PD); its incidence rate is $0.53 \%$ in children. While the underlying mechanism remains unknown, it is speculated to be associated with a pleuroperitoneal communication $[1,2]$.

We present a pediatric case of hydrothorax that occurred as a complication of long-term PD; hydrothorax was confirmed by increased outflow to the thoracic cavity observed on computed tomography (CT) peritoneography with contrast. A PPF was not detected during videoassisted thoracoscopy surgery (VATS) because the case was complicated by pneumonia, with pleural adhesions showing a septated appearance.

\section{Case Presentation}

A 9-year-old Indonesian boy on CAPD was admitted to the emergency unit of our center due to dyspnea, swelling, and increased body weight. There was no fever, cough, or chest pain. Two years previously, he was diagnosed with end-stage renal disease (ESRD) secondary to bilateral renal hypoplasia; since then, he had been receiving CAPD comprising five cycles of 1-L exchanges with 1.5\% dextrose-based solution for 22 months. Furthermore, he had no medical history of heart disease, peritonitis, hernia, thoracic and abdominal trauma, pneumonia, or thoracic and abdominal surgery, except for Tenckhoff catheter insertion. During the previous 3 days, his body weight had increased by $4 \mathrm{~kg}(12 \%)$, and he experienced ultrafiltration failure because although PD fluid at $1 \mathrm{~L}$ per cycle was being infused as usual, the effluent drainage was only approximately $0.6 \mathrm{~L}$ per cycle.

Physical examination revealed a respiratory rate of 34 breaths/min, heart rate of 120 beats/min, and blood pressure of 147/86 mm Hg. Oxygen saturation was $92 \%$ with nasal oxygen at $2 \mathrm{~L} / \mathrm{min}$. Auscultation of the lungs revealed diminished vesicular sounds in the right chest wall. Cardiac findings were normal. Arterial blood gas analysis results were as follows: $\mathrm{pH}: 7.467, \mathrm{pCO}_{2}: 4.51 \mathrm{kPa}, \mathrm{pO}_{2}: 22.52 \mathrm{kPa}$, bicarbonate: $24.8 \mathrm{mmol} / \mathrm{L}$, and base deficit: $2 \mathrm{mmol} / \mathrm{L}$. His hemoglobin level was $131 \mathrm{~g} / \mathrm{L}$, albumin level was $34.6 \mathrm{~g} / \mathrm{L}$, BUN level was 7.08 $\mathrm{mmol} / \mathrm{L}$, and creatinine level was $840.33 \mu \mathrm{mol} / \mathrm{L}$. Chest radiograph revealed right pleural effusion and bilateral pulmonary infiltrates (Fig. 1a). The chest tube drained $500 \mathrm{~mL}$ of transudative fluid. A comparison of serum, pleural fluid, and peritoneal fluid parameters has been presented in Table 1. 


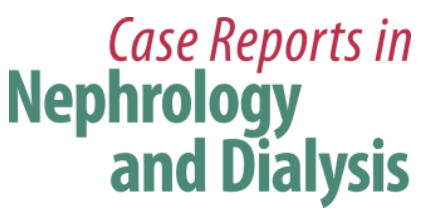

\begin{tabular}{l|l} 
Case Rep Nephrol Dial 2020;10:18-25 \\
\hline DOI: 10.1159/000506119 & $\begin{array}{l}\text { (c) 2020 The Author(s). Published by S. Karger AG, Basel } \\
\text { www.karger.com/cnd }\end{array}$ \\
\hline
\end{tabular}

After the excessive pleural fluid was completely removed, PD was continued via an installed chest tube (Fig. 1b). Intravenous cefotaxime was administered to treat pneumonia that occurred as an additional complication. Recurrent pleural effusion was subsequently found along with ultrafiltration failure. Pleural fluid culture did not show any microbial growth. Hydrothorax secondary to PPF was suspected, and PD was suspended from the 8th day of hospitalization. Hemodialysis (HD) was subsequently initiated.

CT peritoneography was performed on the 9 th day using $300 \mathrm{mg} / \mathrm{mL}$ of iohexol contrast agent immersed in PD fluid. Serial examinations at 30 and 180 min after administering the contrast agent showed excessive fluid in the right pleural cavity (Fig. 1c-h). PPF in the right posterolateral side was suspected.

The patient underwent VATS on the 20th day of hospitalization; however, no fistula was detected in the right chest cavity. Instead, adhesions between the parietal and visceral pleura with septated appearance were observed (Fig. 2a, b). Pleurodesis was performed using $20 \mathrm{~mL}$ of bleomycin for the right diaphragm. Following this, pleural effusion of the right lung resolved (Fig. 3a), and the patient underwent regular HD for 10 weeks. Subsequently, PD was gradually initiated until achieving $1 \mathrm{~L}$ of $1.5 \%$ dextrose-based dialysate solution with five daily exchanges. A 3-year follow-up showed normal PD without any recurrence of hydrothorax (Fig. 3b).

\section{Discussion/Conclusion}

This paper describes a pediatric case of hydrothorax that occurred as a complication of long-term PD. PD is the recommended treatment modality of renal replacement therapy for children with ESRD. It confers a better quality of life [3]; however, it is associated with noninfectious complications, such as catheter obstruction or malfunction, leakage, abdominal wall defect, PPF, hydrocele, ultrafiltration failure, or fluid overload [4].

Symptoms of hydrothorax usually involve respiratory distress, particularly dyspnea [1, 2] - which was present in our patient - as well as diminished vesicular sounds on auscultation and pleural effusion on chest radiograph. However, the underlying mechanism of hydrothorax secondary to PD remains unknown. Hydrothorax is postulated to be associated with a PPF that is formed secondary to a congenital diaphragmatic defect or an acquired defect, resulting in the movement of dialysate from the peritoneum to the pleural cavity [1,2]. Alteration in the pleuroperitoneal pressure gradient secondary to PD that occurred over a 21-month period in our patient may have triggered PPF [5].

CT peritoneography is advantageous for depicting the entire peritoneal and thoracic cavity with minimal costs compared with magnetic resonance peritoneography [6]. Peritoneal scintigraphy may be performed using technetium-99m macroaggregated albumin ( ${ }^{99 \mathrm{~m} T c-}$ MAA) as the contrast agent [5]. We used iohexol as the contrast agent, which highlights a characteristic imaging feature of PPF. Possible defects in the pleura and diaphragm were identified using VATS, but no fistula was observed in the right chest cavity. Instead, adhesions with a septated appearance, presumably secondary to pneumonia, made it difficult to identify the fistula.

Although talc offers better results - as it can inhibit angiogenesis and prevent recurrent pleural effusion [7] - bleomycin was used for pleurodesis in our patient because of the 


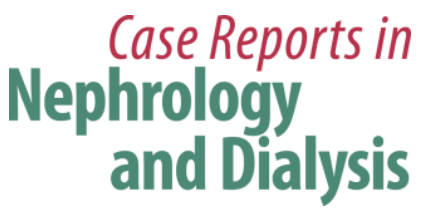

\begin{tabular}{l|l} 
Case Rep Nephrol Dial 2020;10:18-25 \\
\hline DOI: 10.1159/000506119 & $\begin{array}{l}\text { @ } 2020 \text { The Author(s). Published by S. Karger AG, Basel } \\
\text { www.karger.com/cnd }\end{array}$
\end{tabular}

unavailability of talc. Furthermore, bleomycin is less toxic compared with other agents such as povidone iodine [8]. Although bleomycin had a higher cost compared with talc (USD 796 vs. USD 488), bleomycin had a success rate of $87.6 \%$ in preventing the recurrence of effusion in comparison with talc, which was $90.2 \%$ [9]. There have been 5 cases of pleurodesis during 2016-2019 at our center in which bleomycin was used in adults with catamenial pneumotho$\operatorname{rax}(n=1)$ and tumor metastasis-associated spontaneous pneumothorax $(n=4)$ as primary diseases. No side effects or recurrence of pneumothorax was observed during the 1- to 3-year follow-ups. This is the first case of pleurodesis using bleomycin as well as the first case of pleurodesis for suspected PPF in a pediatric patient under long-term PD at our center.

Our findings suggest that discontinuing PD can prevent the occurrence of an expanding effusion. Temporary HD for 4-16 weeks has been previously recommended [10]. Accordingly, we performed HD for 10 weeks and subsequently reinitiated PD. Long-term follow-up revealed no recurrence of hydrothorax. In conclusion, we showed that diagnosing PPF via CT peritoneography using iohexol contrast, followed by a temporary switch of PD to HD, and performing pleurodesis using bleomycin is a potentially valid method for treating a patient with hydrothorax that occurs as a complication of long-term PD in limited settings.

\section{Acknowledgments}

We kindly acknowledge Professor Taralan Tambunan, Professor Partini Pudjiastuti Trihono, Eka Laksmi Hidayati, MD, and Henny Adriani Puspitasari, MD, for their care of the patient in the Department of Child Health. We would also like to express our gratitude to the pediatric dialysis nurses of Cipto Mangunkusumo Hospital (CMH), Yetti Marlina, Mustaqimah, Dorkasturi Sitompul, Meldahania, Ani Suryani, Emma Meida Ekawati, and Resti Fitria Pramandani for their service in the dialysis unit and in maintaining the database, and former pediatric dialysis nurse of $\mathrm{CMH}$, Andri Nurrohman, for carefully performing the hemodialysis sessions. We would also like to thank Elysabeth Muliawan, MD, for her editing service for the English version of this manuscript and Enago (http://www.enago.com) for the careful reading and editing of this paper.

\section{Statement of Ethics}

The research was ethically conducted in accordance with the World Medical Association Declaration of Helsinki. Written informed consent was obtained from the caregiver for publication of this case report and any accompanying images. A copy of the written consent is available for review by the editor of this journal.

\section{Disclosure Statement}

The authors have no conflicts of interest to declare. 


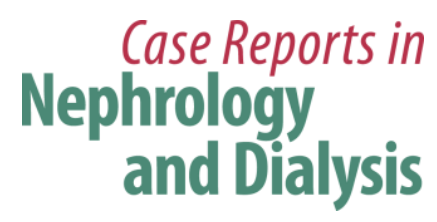

\begin{tabular}{l|l} 
Case Rep Nephrol Dial 2020;10:18-25 \\
\hline DOI: 10.1159/000506119 & $\begin{array}{l}\text { @ } 2020 \text { The Author(s). Published by S. Karger AG, Basel } \\
\text { www.karger.com/cnd }\end{array}$
\end{tabular}

\section{Funding Sources}

The authors have no funding sources to declare.

\section{Author Contributions}

C.G.A. and F.H.F.R. performed the literature search, data collection, data analysis, and data interpretation and wrote the first draft of the manuscript. E.K.B. and M.A.P. performed the data collection and data analysis, reviewed the manuscript, and approved the final version. S.O.P critically reviewed the manuscript. All authors read and approved the final manuscript.

\section{References}

1 Dufek S, Holtta T, Fischbach M, Ariceta G, Jankauskiene A, Cerkauskiene R, et al.; European Paediatric Dialysis Working Group. Pleuro-peritoneal or pericardio-peritoneal leak in children on chronic peritoneal dialysis-A survey from the European Paediatric Dialysis Working Group. Pediatr Nephrol. 2015 Nov;30(11):2021-7.

2 Kennedy C, McCarthy C, Alken S, McWilliams J, Morgan RK, Denton M, et al. Pleuroperitoneal leak complicating peritoneal dialysis: a case series. Int J Nephrol. 2011;2011:526753.

3 Brownbridge G, Fielding DM. Psychosocial adjustment to end-stage renal failure: comparing haemodialysis, continuous ambulatory peritoneal dialysis and transplantation. Pediatr Nephrol. 1991 Sep;5(5):612-6.

4 Ambarsari CG, Trihono PP, Kadaristiana A, Tambunan T, Mushahar L, Puspitasari HA, et al. Five-year experience of surgical complications of continuous ambulatory peritoneal dialysis in children: a single center experience in a developing country. Med J Indones. 2019;28(4):329-37.

5 Fujino Y, Kawada N, Ito K, Katsura H, Maeda H, Mitsumoto K, et al. Recurrent pleuroperitoneal leak caused by diaphragm blebs in a peritoneal dialysis patient: A case report with literature review. Ren Replace Ther. 2018 Oct. Available from: https://doi.org/10.1186/s41100-018-0181-8.

6 Bai J, Zhong H, Liu R. Peritoneal-mediastinal communication complication of peritoneal dialysis demonstrated by multidetector-row CT peritoneography: A case report. Egypt J Radiol Nucl Med. 2015 Dec;46(4):893-6.

7 Rodriguez-Panadero F, Montes-Worboys A. Mechanisms of pleurodesis. Respiration. 2012;83(2):91-8.

8 Alavi AA, Eshraghi M, Rahim MB, Meysami AP, Morteza A, Hajian H. Povidone-iodine and bleomycin in the management of malignant pleural effusion. Acta Med Iran. 2011;49(9):584-7.

9 Haddad FJ, Younes RN, Gross JL, Deheinzelin D. Pleurodesis in patients with malignant pleural effusions: talc slurry or bleomycin? Results of a prospective randomized trial. World J Surg. 2004 Aug;28(8):749-53.

10 Krivokuca I, Lammers JW, Kluin J. Peritoneal dialysis-An unusual cause of pleural effusion ("sweet hydrothorax"). Respir Med CME. 2009 Dec;2(4):197-200. 

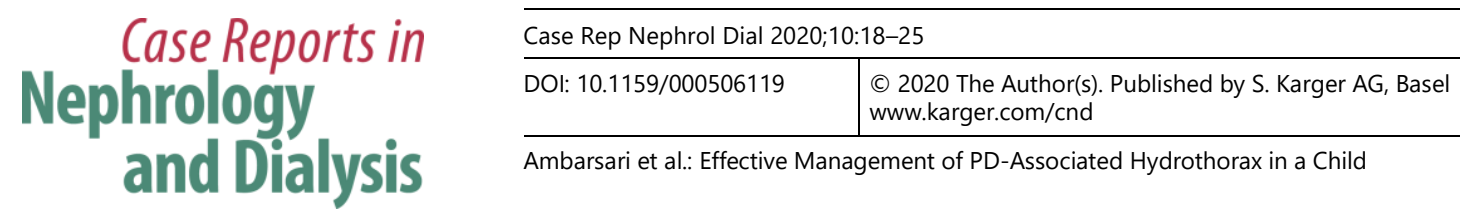

Ambarsari et al.: Effective Management of PD-Associated Hydrothorax in a Child

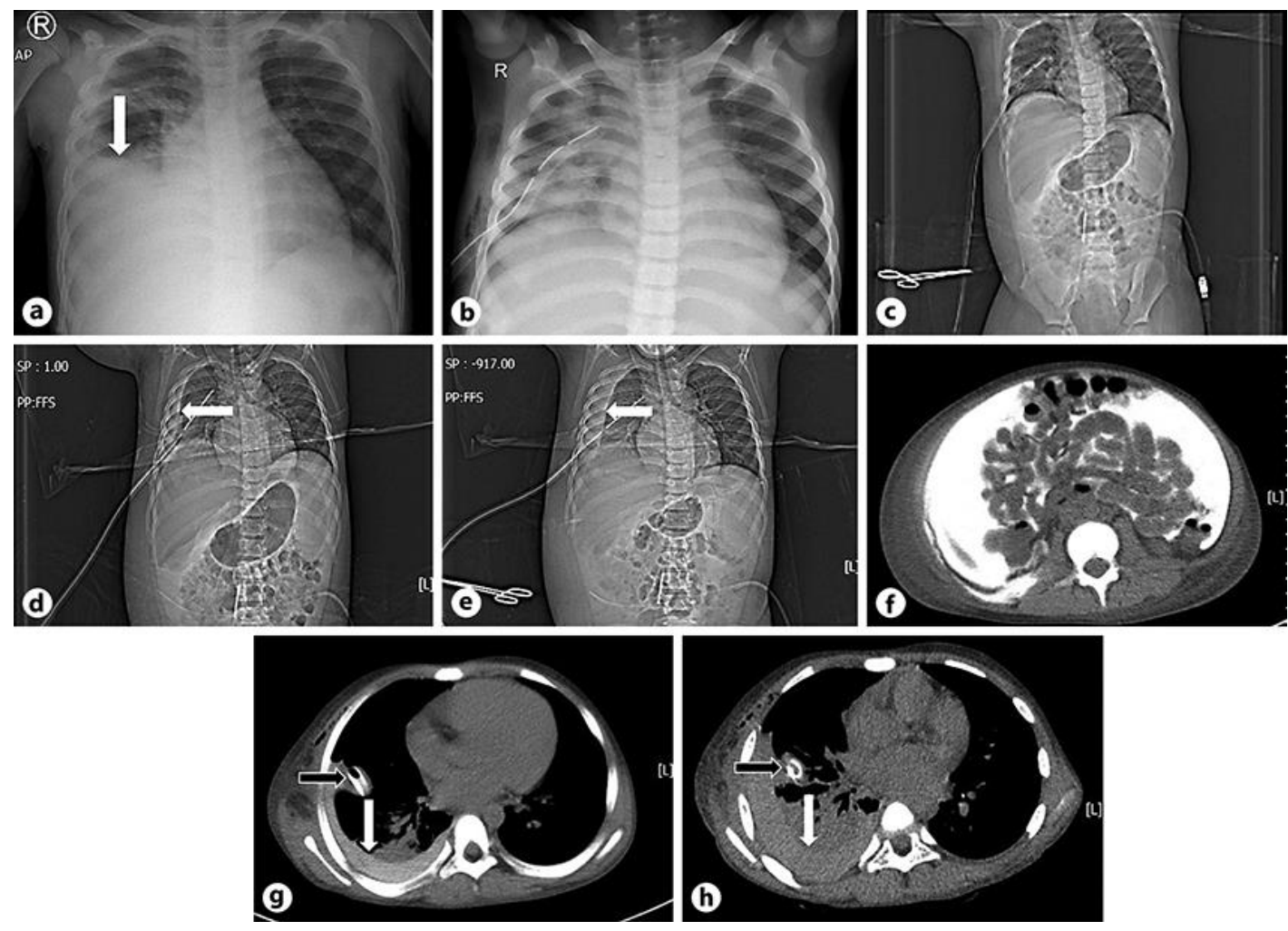

Fig. 1. Imaging series of a 9-year-old male patient who experienced hydrothorax while on CAPD. a An initial chest radiograph showed right pleural effusion. $\mathbf{b}$ The pleural effusion resolved, and PD was performed with chest tube still attached. Note the presence of pneumonia. c Chest radiograph immediately prior to CT peritoneography. Chest radiograph shows increased presence of fluid in the right pleural cavity at the 30th min (d) and 180th min (e) (white arrows). f CT peritoneography of the peritoneum surrounded by peritoneal dialysis solution containing contrast media shows increased presence of fluid in the right pleural cavity at the 30th min (g) and 180th min (h) (white arrows), with black arrows indicating the position of the chest tube. 


\section{Case Reports in Nephrology and Dialysis}
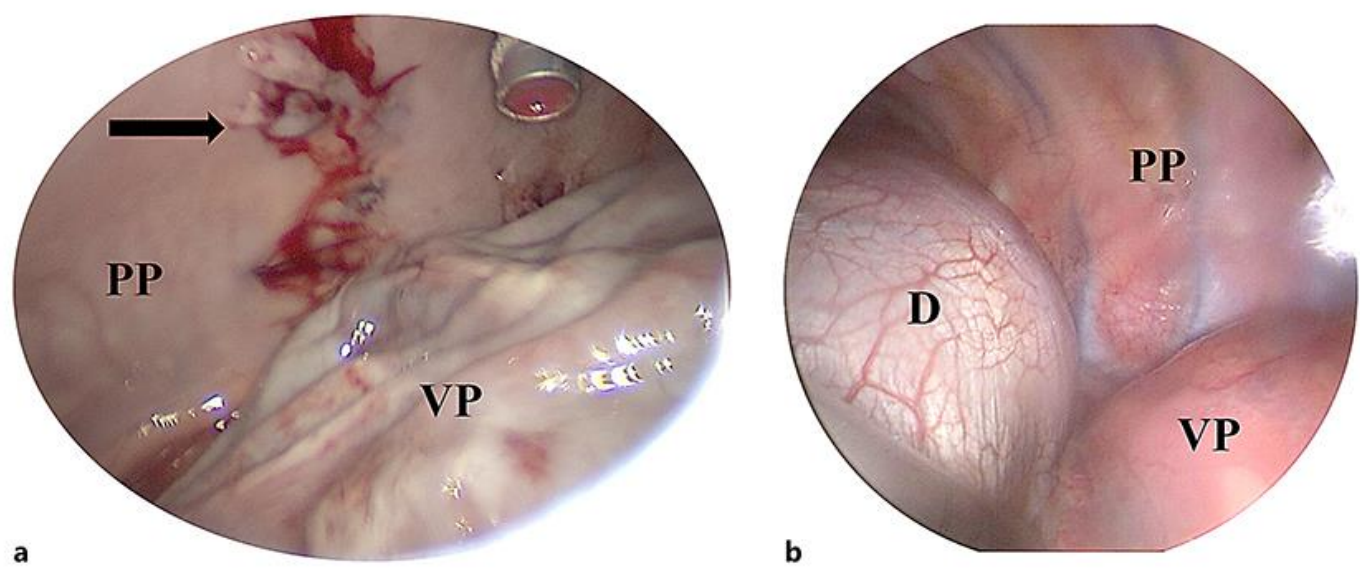

Fig. 2. a VATS shows inflammation in the region following septa removal prior to adhesiolysis. $\mathbf{b}$ VATS showed no defects over the diaphragm, and fistula was not seen.
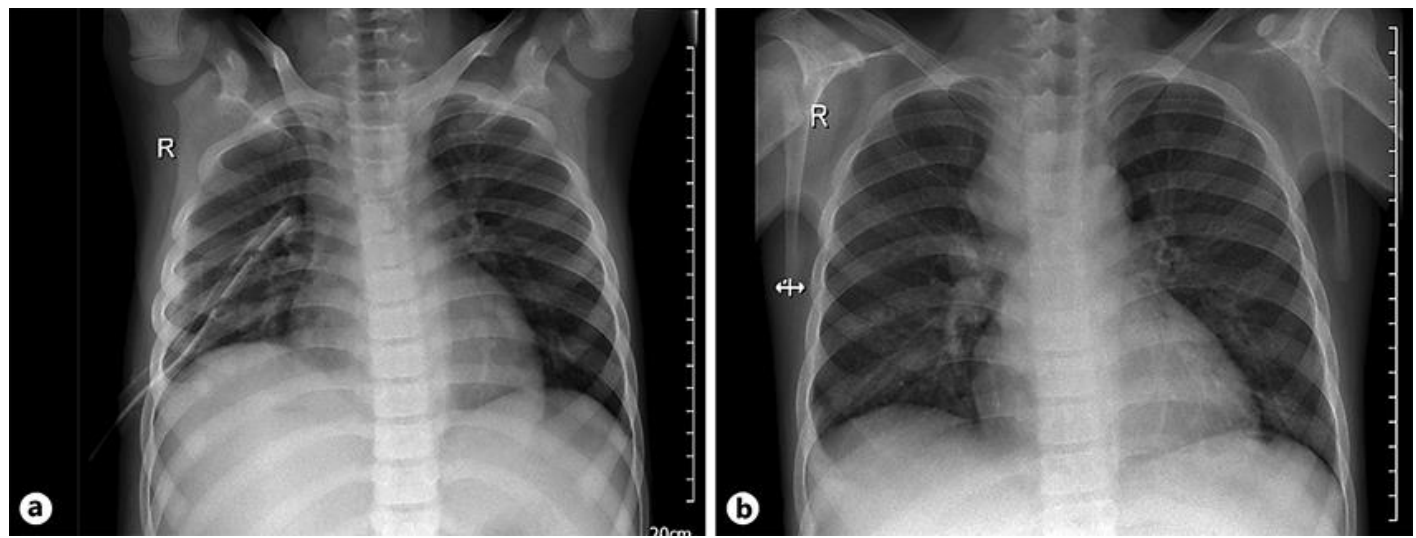

Fig. 3. a First follow-up chest radiograph after PD suspension and HD initiation showed reduction of pleural effusion. $\mathbf{b}$ The 3-year follow-up chest radiograph showed complete resolution of pleural effusion with no recurrence. 


\section{Case Reports in Nephrology and Dialysis}

\begin{tabular}{l|l} 
DOI: $10.1159 / 000506119$ & (c) 2020 The Author(s). Published by S. Karger AG, Basel
\end{tabular} www.karger.com/cnd

Ambarsari et al.: Effective Management of PD-Associated Hydrothorax in a Child

Table 1. Serum, peritoneal, and pleural fluid biochemistry

\begin{tabular}{lccll}
\hline Specimen & $\begin{array}{l}\text { Glucose, } \\
\mathrm{mmol} / \mathrm{L}\end{array}$ & $\begin{array}{l}\mathrm{LDH}, \\
\mu \mathrm{kat} / \mathrm{L}\end{array}$ & $\begin{array}{l}\text { Protein, } \\
\mathrm{g} / \mathrm{L}\end{array}$ & $\begin{array}{l}\text { Cell count, } \\
/ \mu \mathrm{L}\end{array}$ \\
\hline Reference & $3.9-6.1$ & $1.7-3.4$ & $62-85$ & \\
Serum & 5.49 & 12.11 & 54 & \\
Peritoneal fluid & 38.57 & 0.1 & 2 & 2 \\
Pleural fluid & 8.27 & 1.02 & 3 & 26 \\
\hline
\end{tabular}

LDH, lactate dehydrogenase. 